\title{
Feeding behaviour and energy balance in 4- to 6-month-old infants: adaptive changes during exclusive breast-feeding
}

\author{
S. B. Nielsen ${ }^{1}$, J. C. K. Wells ${ }^{2}$, M. S. Fewtrell ${ }^{2}$ and J. J. Reilly ${ }^{1}$ \\ ${ }^{1}$ University of Glasgow, Glasgow, UK and ${ }^{2}$ University College London, London, UK
}

The WHO recommends exclusive breast-feeding (EBF) until 6 months of age ${ }^{(1)}$. EBF indisputably has many advantages for mother and infant, but a systematic review of cross-sectional studies has found only sparse data on energy transfer from mother to baby after age 5 months ${ }^{(2)}$, and has suggested uncertainty as to whether sufficient adaptive changes take place during EBF to accommodate increasing infant energy needs during EBF to 6 months ${ }^{(3)}$. Longitudinal studies have failed to find significant changes in breast milk volume or energy content after 4 months of lactation ${ }^{(2)}$. Most studies have used test weighing combined with milk sampling, which may interfere with breast-feeding routines, and provide unrepresentative estimates of the energy content of breast milk, so there is a need for more evidence using isotopic techniques. In the present investigation isotopic techniques have been used in cross-sectional and longitudinal studies in order to identify the adaptive changes that occur to make EBF possible for 6 months. Data from the cross-sectional study are presented here.

The metabolisable energy content of breast milk was examined in 21 infants at 12.3 (SD 0.6) weeks of age ${ }^{(4)}$. A dose-to-infant of doublylabelled water was administered through a feeding tube, and disappearance rates of Deuterium and Oxygen-18 was measured from daily urine samples for the subsequent 7 days, as described previously ${ }^{(4)}$.

Mean breast milk intake was 879 (SD 121) $\mathrm{ml} / \mathrm{d}$ and the metabolisable energy density content was $2.59 \mathrm{~kJ}(0.62 \mathrm{kcal}) / \mathrm{ml}$ breast milk (Table).

\begin{tabular}{lcc}
\hline & Mean & SD \\
\hline Infant characteristics & & \\
$\quad$ Weight of infants (kg) & 6.03 & 0.65 \\
$\begin{array}{l}\text { Doubly-labelled-water-derived data }(n \text { 21) } \\
\text { Milk volume intake (ml/d) }\end{array}$ & 879 & 121 \\
Metabolisable energy density: $\mathrm{kJ} / \mathrm{ml}$ & 2.59 & 0.48 \\
$\quad \mathrm{kcal} / \mathrm{ml}$ & 0.62 & 0.11 \\
\hline
\end{tabular}

This cross-sectional study suggests that the metabolisable energy density of breast milk may be lower than literature values, which are commonly found to be $2.9-3.0 \mathrm{~kJ} / \mathrm{ml}$ (ranging from $2.6-3.3 \mathrm{~kJ} / \mathrm{ml})^{(2)}$. Increasing infant energy needs during EBF could be met by increased breast milk energy density and/or milk volume. Alternatively, infant growth rate may decrease, delaying the point at which breast milk energy supply becomes insufficient. To investigate this it is necessary to conduct a longitudinal observational study on the energetics, growth and body composition of healthy EBF infants from 4 to 6 months of age, using the doubly-labelled water method, and such a study is underway.

1. World Health Organization (2002) Infant and Young Child Nutrition. Global Strategy on Infant and Young Child Feeding. Geneva: WHO.

2. Reilly JJ, Ashworth S \& Wells JC (2005) Br J Nutr 94, 56-63.

3. Reilly JJ \& Wells JC (2005) Br J Nutr 94, 869-872.

4. Wells JCK \& Davies PSW (1995) Am J Hum Biol 7, 85-92. 